\title{
Impact of socioeconomic deprivation on maternal perinatal mental illnesses presenting to UK general practice
}

\begin{abstract}
\section{Background}

Although maternal perinatal mental illnesses commonly present to and are primarily treated in general practice, few population-based estimates of this burden exist, and the most affected socioeconomic groups of pregnant women remain unclear.

\section{Aim \\ To provide estimates of maternal depression, anxiety and serious mental illness (SMI) in UK general practice and quantify impacts of socioeconomic deprivation.}

\section{Design and setting}

Cross-sectional analysis of prospectively recorded general practice records from a UK-wide database

\section{Method}

A pregnancy ending in live birth was randomly selected for every woman of childbearing age, 1994-2009. Prevalence and diagnostic overlap of mental illnesses were calculated using a combination of medical diagnoses and psychotropic drug prescriptions. Socioeconomic deprivation was assessed using multivariate logistic regression, adjusting for calendar period and pregnancy history.

\section{Results}

Among 116457 women, 5.1\% presented with antenatal depression and $13.3 \%$ with postnatal depression. Equivalent figures for anxiety were $2.6 \%$ and $3.7 \%$ and for SMI $1 / 1000$ and $2 / 1000$ women. Socioeconomic deprivation increased the risk of all mental illnesses, although this was more marked in older women. Those age $35-45$ years in the most deprived group had 2.63 times the odds of antenatal depression (95\% confidence interval $[\mathrm{Cl}]=2.22$ to 3.13 ) compared with the least deprived; in women aged

15-25 years the increased odds associated with deprivation was more modest lodds ratio $=1.35$, $95 \% \mathrm{Cl}=1.07$ to 1.70 ). Similar patterns were found for anxiety and SMI.

\section{Conclusion}

Strong socioeconomic inequalities in perinatal mental illness persist with increasing maternal age. Targeting detection and effective interventions to high-risk women may reduce inequity and avoid substantial psychiatric morbidity.

\section{Keywords}

general practice; mental disorder; mothers; socioeconomic status.

\section{INTRODUCTION}

Perinatal mental illness, especially depression, is a leading cause of maternal morbidity and mortality in high-income countries $^{1,2}$ and has unfavourable impacts on short-term and long-term physical and mental health of offspring. ${ }^{3-5}$ Guidance from the UK's National Institute for Health and Clinical Excellence (NICE) has emphasised that perinatal mental illness is one of the most important issues in women's health ${ }^{6}$ yet up-to-date estimates of these conditions identified or treated at primary care level are not available. Although a recent systematic review ${ }^{7}$ reported $6.5-12.9 \%$ of women had depression during pregnancy and in the year postpartum, there are few estimates of maternal anxiety and serious mental illness (SMI; for example, bipolar disorder and psychosis) and hardly any estimates of concurrent diagnoses of different mental illnesses perinatally.

In addition, the latest UK national mental illness strategy ${ }^{8}$ highlighted the importance of reducing health inequalities as a key objective to promote mental wellbeing in the population, yet there remains a need for government to narrow the gap between policies and actions to effectively identify and treat those who are most vulnerable. While an association between mental illness and greater socioeconomic deprivation in the general population has been well documented, ${ }^{9}$ fewer studies have assessed

L Ban, MSc; doctoral student; JE Gibson, PhD, research fellow; L Fiaschi, $P h D$, research associate and data analyst; LJ Tata, PhD, lecturer in epidemiology, Division of Epidemiology \& Public Health, Nottingham City Hospital, University of Nottingham, Nottingham. J West, PhD, clinical associate professor \& reader in epidemiology, Division of Epidemiology \& Public Health, Nottingham City Hospital, University of Nottingham and Nottingham Digestive Diseases Centre Biomedical Research Unit, Queen's Medical Centre, Nottingham. MR Oates, OBE, FRCPsych FRCOG, consultant perinatal psychiatrist, NHS East Midlands Perinatal Mental Health Clinical Network, Duncan Macmillan House, Nottingham. this in the perinatal period and results are inconsistent. ${ }^{10-13}$ Furthermore, evidence that impacts of material deprivation may vary with age ${ }^{14}$ has not been assessed in pregnant women.

As most mental illness is detected and treated in general practice, and it provides the gateway to secondary care, a large population-based study was conducted to obtain current estimates of perinatal depression, anxiety, and SMI identified in UK general practice. Variation in illness was quantified by socioeconomic status and the extent of comorbidity or diagnostic overlap.

\section{METHOD}

Dataset and study population

Data from The Health Improvement Network (THIN) database of anonymised electronic patient records covering 446 general practices throughout the UK were used. THIN has a high standard of validated medical diagnoses, events, symptoms, and drug prescriptions. ${ }^{15}$ The study population comprised women aged $15-45$ years with at least one recorded pregnancy ending in live birth between 1994 and 2009. To ensure no clustering effects, one pregnancy for each woman was randomly selected.

\section{Measuring mental illness in and around pregnancy}

In UK general practice it is common for patients to be prescribed psychotropic drugs

\section{Address for correspondence}

Laila J Tata, Division of Epidemiology \& Public Health, University of Nottingham, Clinical Sciences Building, City Hospital, Hucknall Road, Nottingham, NG5 1PB, UK.

E-mail: laila.tataanottingham.ac.uk

Submitted: 29 October 2011; Editor's response: 9 December 2011; final acceptance: 28 March 2012

\section{CBritish Journal of General Practice}

This is the full-length article (published online 1 Oct 2012) of an abridged version published in print. Cite this article as: $\mathbf{B r} \mathbf{J}$ Gen Pract 2012; DOI: 10.3399/bjgp12X656801 


\section{How this fits in \\ Maternal perinatal mental illness has been highlighted as one of the most important issues in women's health worldwide and there is considerable burden across the severity spectrum of maternal mental illnesses in UK general practice for women of all ages. Greater recognition that women in the most socioeconomically-deprived groups are at high risk is required at policy level; this should emphasise the need for trials of methods to effectively identify women and interventions to prevent and treat perinatal mental illness in high risk women in the primary care setting.}

\section{Box 1. Detailed definitions of mental illness within periods in and around pregnancy}

\section{Depression}

Women were identified as having clinically-recognised depression in each period if they had records of depression and/or antidepressant prescriptions. Because antidepressants are prescribed for other menta illnesses (for example, anxiety), women who had been prescribed antidepressants but had no diagnosis of depression in their medical records were not included.

\section{Anxiety}

Women were identified as having clinically-recognised anxiety if they had records of anxiety and/or anxiolytic prescriptions during each period, excluding women who were prescribed anxiolytics with no diagnosis of anxiety throughout their medical record. Secondly, since anxiety is commonly treated using antidepressants, women with antidepressant prescriptions during the period and a diagnosis of anxiety at any time but without records of depression were identified.

\section{Serious mental illness}

Although serious mental illnesses are considered clinically to have life-long impact and NICE guidelines indicate the importance of knowing a woman's history of psychotic illness, ${ }^{6}$ this study focused on evidence of currently recognised illness. Women were considered to have clinically-recognised bipolar disorder during each period if they had medical records of the illness and/or prescriptions of lithium or mood stabilisers during that time. Since mood stabilisers are also used for other conditions (for example, epilepsyl, women prescribed mood stabilisers but with no diagnoses of bipolar disorder in their medical records were excluded. Women with schizophrenia and other psychotic disorders were identified in the same way and, as these are rare conditions, they were grouped together as 'serious mental illness'. without direct diagnostic indication for the prescription, likely reflecting the diagnostic pathway (for example, prescriptions of psychotropic drugs as part of diagnostic procedure) and routine clinical practice (for example, a doctor with knowledge of their patient's clinical history will not need to record a new diagnosis of depression with each prescription for effective clinical care). Furthermore, individuals may receive more than one type of diagnosis, concurrently or at different times during their life. Therefore a comprehensive approach to define and distinguish between different types of mental illness in women's records was adopted by using a combination of medical diagnoses and psychotropic drug prescriptions. The prevalence of clinicallydiagnosed perinatal mental illness with or without treatment during the 9 months before pregnancy, during pregnancy (antenatal period) and during the 9 months after pregnancy (postnatal period) was estimated. Periods of 9-months were used as they were similar in length to the average pregnancy, minimising potential effects of different period lengths on prevalence estimates. Definitions of how clinically-recognised depression, anxiety, and SMI (bipolar disorder, schizophrenia, other psychotic disorders) were defined in and around pregnancy are in Box 1.

\section{Statistical analyses}

The prevalence of each mental illness was calculated as a proportion of all women during the periods before, during and after pregnancy. To provide estimates of overlapping illness, proportions of women with two or more different concurrent diagnoses were calculated. To estimate newly-diagnosed mental illness before, during and after pregnancy, data were

Table 1. Prevalence of maternal depression, anxiety and serious mental illness ${ }^{\mathrm{a}}$ presenting to UK general practice in and around pregnancy $(n=116457)$

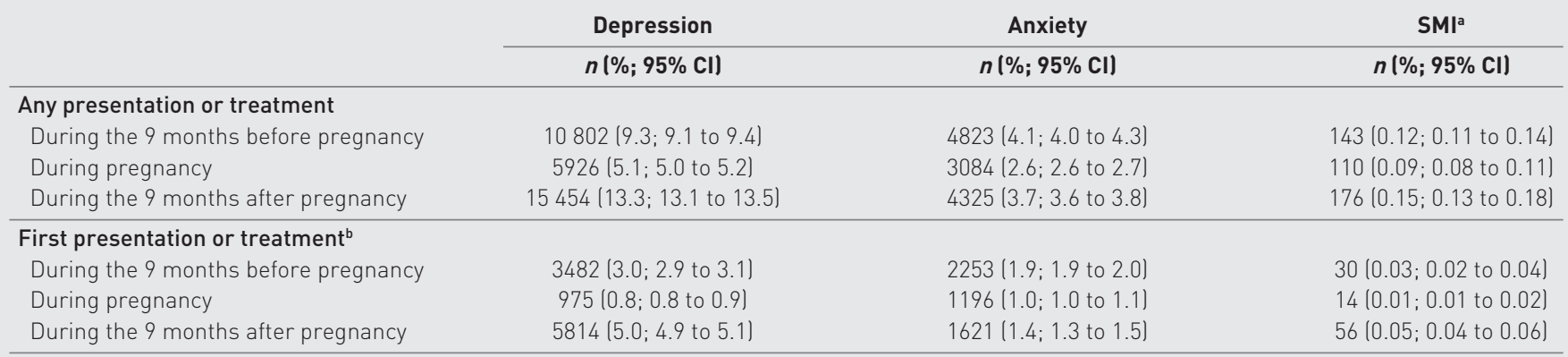

aSMI includes bipolar disorder, schizophrenia or other related psychotic disorders. ${ }^{b}$ Prevalence estimates are for presentation or treatment only when it first appeared in a woman's record during the respective 9-month period, excluding any women with a history of the relevant mental illness. SMI = serious mental illness. 


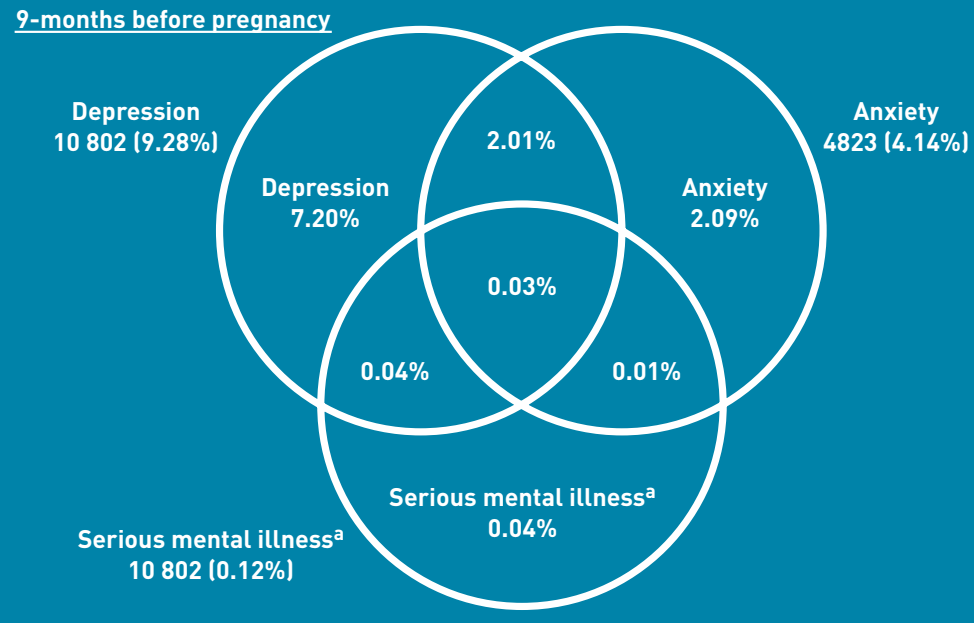

with socioeconomic deprivation, measured using household-level Townsend Index of Deprivation. To maintain anonymity in THIN, patients' home postcodes are assigned a quintile of Townsend Index before data leave the general practice. As quintiles are based on census data distribution, they are representative of women's relative socioeconomic position at national level. Given the effect of socioeconomic deprivation on mental illness could vary substantially across age, ${ }^{14}$ effect modification was assessed using the likelihood ratio test and presented prevalence estimates were used to show absolute risks of clinicallyrecognised mental illness in each quintile stratified by maternal age (categorised as 15-24, 25-34, 35-45 years) alongside ORs adjusted for calendar period and women's previously recorded live births. This was reassessed for women's first clinically diagnosed mental illnesses during and after pregnancy.

\section{RESULTS}

A total of 116457 women with at least one pregnancy ending in a live birth were identified. Median age at the end of pregnancy was 31 years (interquartile range 26-35 years) and the numbers (proportions) of pregnant women aged 15-24, 25-35, and 35-44 years were 21341 (18.3\%), 64214 (55.1\%) and 30902 (26.5\%) respectively. Of all women, 23.2\% (26 984) were from the least socioeconomically-deprived group whereas 14.2\% (16 524) were from the most socioeconomically-deprived group (5.3\% (6172) had no socioeconomic group recorded).

Table 1 shows the clinical presentation of all mental illnesses in and around pregnancy. Compared with maternal depression in the period before pregnancy (9.3\%), prevalence was lower during pregnancy $(5.1 \%)$ and higher postpartum (13.3\%). For anxiety and SMI, prevalence before pregnancy was similar to after although clinical recording for both was lower during pregnancy $(2.6 \%$ and $0.09 \%$ respectively). Compared with all clinical presentations, first presentations were less common but had similar prevalence patterns over the three periods, such that they were still lowest in the antenatal period (Table 1). Most women with SMI also had clinically-recognised depression or anxiety. yet most diagnostic overlap was between common mental illnesses with nearly $20 \%$ of women with antenatal depression also having anxiety (Figure 1).

Tables 2-4 show absolute risks and adjusted ORs of clinically-recognised

restricted to women whose first mental illness recording fell in each 9-month period. Logistic regression in Stata SE (version 11.1) was used to calculate odds ratios (ORs) for the association of each mental illness 
Table 2. Absolute risks and adjusted odds ratios for maternal depression associated with socioeconomic status, stratified by maternal age $\left(n=110285^{\text {a) }}\right.$

\begin{tabular}{|c|c|c|c|c|c|c|c|c|c|c|c|c|}
\hline \multirow{3}{*}{$\begin{array}{l}\text { Socioeconomic status } \\
\text { (deprivation quintile) }\end{array}$} & \multicolumn{11}{|c|}{ Maternal age } & \multirow[b]{3}{*}{$A O R^{d}(95 \% \mathrm{Cl})$} \\
\hline & \multicolumn{3}{|c|}{$15-24$ years } & \multirow[b]{2}{*}{$\mathrm{AOR}^{\mathrm{d}}(95 \% \mathrm{Cl})$} & \multicolumn{3}{|c|}{$25-34$ years } & \multicolumn{4}{|c|}{$35-45$ years } & \\
\hline & $N$ & $n f$ & $\%$ & & $N^{p}$ & $n f$ & $\%$ & $\operatorname{AOR}^{\mathrm{d}}(95 \% \mathrm{Cl})$ & $N$ & $n f$ & $\%$ & \\
\hline During pregnancye & 20176 & 1223 & 6.1 & & 60722 & 2952 & 4.9 & & 29387 & 1416 & 4.8 & \\
\hline 1 (least deprivation) ( $N=26984$ ) & 1843 & 94 & 5.1 & 1.00 & 15732 & 492 & 3.1 & 1.00 & 9409 & 325 & 3.5 & 1.00 \\
\hline $2(N=21978)$ & 2479 & 109 & 4.4 & 0.85 (0.64 to 1.13 ) & 12655 & 482 & 3.8 & 1.22 (1.07 to 1.38 ) & 6844 & 278 & 4.1 & 1.18 (1.00 to 1.39 ) \\
\hline $3(N=23028)$ & 4052 & 240 & 5.9 & 1.15 (0.90 to 1.47$)$ & 13069 & 661 & 5.1 & 1.61 (1.43 to 1.82 ) & 5907 & 287 & 4.9 & 1.41 (1.20 to 1.66$)$ \\
\hline $4(N=21771)$ & 5838 & 364 & 6.2 & 1.21 (0.95 to 1.52 ) & 11452 & 707 & 6.2 & 1.93 (1.72 to 2.17$)$ & 4481 & 276 & 6.2 & 1.77 (1.50 to 2.09$)$ \\
\hline $\begin{array}{l}5 \text { (most deprivation) ( } N=16524) \\
P \text {-value for trend }\end{array}$ & 5964 & 416 & 7.0 & $\begin{array}{c}1.35(1.07 \text { to } 1.70) \\
<0.001^{\dagger}\end{array}$ & 7814 & 610 & 7.8 & $\begin{array}{c}2.39 \text { (2.11 to } 2.70 \text { ) } \\
<0.001^{1}\end{array}$ & 2746 & 250 & 9.1 & $\begin{array}{c}2.63(2.22 \text { to } 3.13) \\
<0.001^{\mathrm{f}}\end{array}$ \\
\hline $\begin{array}{l}\text { During the } 9 \text { months } \\
\text { after pregnancy }\end{array}$ & 20176 & 3550 & 17.6 & & 60722 & 7840 & 12.9 & & 29387 & 3235 & 11.0 & \\
\hline 1 (least deprivation) ( $N=26984)$ & 1843 & 236 & 12.8 & 1.00 & 15732 & 1576 & 10.0 & 1.00 & 9409 & 836 & 8.9 & 1.00 \\
\hline $2(N=21978)$ & 2479 & 368 & 14.8 & $1.19(1.00$ to 1.41$)$ & 12655 & 1401 & 11.1 & $1.12(1.04$ to 1.21$)$ & 6844 & 681 & 10.0 & 1.14 (1.02 to 1.27$)$ \\
\hline $3(N=23028)$ & 4052 & 708 & 17.5 & 1.44 (1.23 to 1.69$)$ & 13069 & 1708 & 13.1 & 1.35 (1.25 to 1.45$)$ & 5907 & 640 & 10.8 & 1.25 (1.12 to 1.39 ) \\
\hline $4(N=1771)$ & 5838 & 1100 & 18.8 & 1.56 (1.34 to 1.82 ) & 11452 & 1766 & 15.4 & 1.62 (1.50 to 1.74$)$ & 4481 & 579 & 12.9 & 1.51 (1.35 to 1.69 ) \\
\hline 5 (most deprivation) $(N=6524)$ & 5964 & 1138 & 19.1 & 1.58 (1.36 to 1.84$)$ & 7814 & 1389 & 17.8 & 1.88 (1.74 to 2.03) & 2746 & 499 & 18.2 & 2.25 (1.99 to 2.53) \\
\hline$P$-value for trend & & & & $<0.001^{\dagger}$ & & & & $<0.001^{\dagger}$ & & & & $<0.001^{f}$ \\
\hline
\end{tabular}

${ }^{2} .3 \%(6,172)$ of the original population $(116457)$ had no socioeconomic status recorded. ${ }^{b}$ Number of women in each deprivation quintile. ${ }^{c}$ Number of women with depression. ${ }^{d}$ Odds ratio and $95 \% \mathrm{Cl}$ adjusted for calendar time and number of previous known live births. ${ }^{2}$ Likelihood ratio test for interaction between deprivation quintile and age group: during pregnancy $\mathrm{P}<0.001$; after pregnancy $\mathrm{P}<0.001$. $\mathrm{P}$-value for trend from least to greatest deprivation excluding women with missing information for socioeconomic status. $A O R=$ adjusted odds ratio

Table 3. Absolute risks and adjusted odds ratios for maternal anxiety associated with socioeconomic status, stratified by maternal age $\left(N=110285^{a}\right)$

\begin{tabular}{|c|c|c|c|c|c|c|c|c|c|c|c|c|}
\hline \multirow{3}{*}{$\begin{array}{l}\text { Socioeconomic status } \\
\text { (deprivation quintile) }\end{array}$} & \multicolumn{11}{|c|}{ Maternal age } & \multirow[b]{3}{*}{$\operatorname{AOR}^{d}(95 \% \mathrm{Cl})$} \\
\hline & \multicolumn{3}{|c|}{$15-24$ years } & \multirow[b]{2}{*}{$\operatorname{AOR}^{d}(95 \% \mathrm{Cl})$} & \multicolumn{3}{|c|}{$25-34$ years } & \multicolumn{4}{|c|}{$35-45$ years } & \\
\hline & $N^{p}$ & $n$ & $\%$ & & $N^{p}$ & $n$ & $\%$ & $\mathrm{AOR}^{\mathrm{d}}(95 \% \mathrm{Cl})$ & $N$ & $n$ & $\%$ & \\
\hline During pregnancye & 20176 & 559 & 2.8 & & 60722 & 1593 & 2.6 & & 29387 & 767 & 2.6 & \\
\hline 1 (least deprivation) ( $N=26$ 984) & 1843 & 41 & 2.2 & 1.00 & 15732 & 302 & 1.9 & 1.00 & 9409 & 189 & 2.0 & 1.00 \\
\hline $2(N=21978)$ & 2479 & 70 & 2.8 & 1.27 (0.86 to 1.88$)$ & 12655 & 293 & 2.3 & 1.21 (1.03 to 1.42$)$ & 6844 & 135 & 2.0 & 0.98 (0.78 to 1.23 ) \\
\hline $3(N=23028)$ & 4052 & 116 & 2.9 & 1.29 (0.90 to 1.85$)$ & 13069 & 348 & 2.7 & $1.39(1.19$ to 1.62$)$ & 5907 & 155 & 2.6 & 1.31 (1.06 to 1.62$)$ \\
\hline $4(N=1771)$ & 5838 & 135 & 2.3 & $1.03(0.72$ to 1.47$)$ & 11452 & 345 & 3.0 & 1.56 (1.33 to 1.83$)$ & 4481 & 153 & 3.4 & 1.71 (1.38 to 2.12) \\
\hline 5 (most deprivation) ( $N=16524)$ & 5964 & 197 & 3.3 & 1.49 (1.06 to 2.09$)$ & 7814 & 305 & 3.9 & 2.02 (1.72 to 2.38 ) & 2746 & 135 & 4.9 & $2.48(1.98$ to 3.11$)$ \\
\hline$P$-value for trend & & & & $0.06^{\mathrm{f}}$ & & & & $<0.001^{\dagger}$ & & & & $<0.001^{\dagger}$ \\
\hline $\begin{array}{l}\text { During the } 9 \text { months } \\
\text { after pregnancye }\end{array}$ & 20176 & 804 & 4.0 & & 60722 & 2330 & 3.8 & & 29387 & 974 & 3.3 & \\
\hline 1 (least deprivation) ( $N=26984$ ) & 1843 & 65 & 3.5 & 1.00 & 15732 & 477 & 3.0 & 1.00 & 9409 & 258 & 2.7 & 1.00 \\
\hline $2(N=21978)$ & 2479 & 82 & 3.3 & 0.93 (0.67 to 1.30$)$ & 12655 & 425 & 3.4 & 1.11 (0.97 to 1.27$)$ & 6844 & 200 & 2.9 & 1.07 (0.88 to 1.29 ) \\
\hline $3(N=23028)$ & 4052 & 165 & 4.1 & 1.16 (0.86 to 1.55$)$ & 13069 & 502 & 3.8 & $1.27(1.12$ to 1.44$)$ & 5907 & 184 & 3.1 & 1.14 (0.94 to 1.38 ) \\
\hline $4(N=21771)$ & 5838 & 230 & 3.9 & 1.11 (0.84 to 1.47$)$ & 11452 & 521 & 4.6 & 1.50 (1.32 to 1.70$)$ & 4481 & 179 & 4.0 & 1.46 (1.20 to 1.77$)$ \\
\hline 5 (most deprivation) ( $N=16524)$ & 5964 & 262 & 4.4 & 1.24 (0.94 to 1.63$)$ & 7814 & 405 & 5.2 & 1.69 (1.47 to 1.94$)$ & 2746 & 153 & 5.6 & 2.06 (1.68 to 2.53) \\
\hline$P$-value for trend & & & & $0.06^{4}$ & & & & $<0.001^{\dagger}$ & & & & $<0.001^{f}$ \\
\hline
\end{tabular}

${ }^{2} 5.3 \%$ (6172) of the original population $(116457)$ had no socioeconomic status recorded. ${ }^{b}$ Number of women in each deprivation quintile. ${ }^{c}$ Number of women with anxiety. ${ }^{d}$ Odds ratio and $95 \% \mathrm{Cl}$ adjusted for calendar time and number of previous known live births. ${ }^{2}$ Likelihood ratio test for interaction between deprivation quintile and age group: during pregnancy $\mathrm{P}<0.001$; after pregnancy $\mathrm{P}=0.09 .{ }^{\mathrm{f}} \mathrm{P}$-value for trend from least to greatest deprivation excluding women with missing information for socioeconomic status. $A O R=$ adjusted odds ratio.

depression, anxiety, and SMI with socioeconomic deprivation, stratified by maternal age. The prevalence of maternal depression and anxiety was highest in the youngest women and lowest in the oldest women, although this pattern varied considerably by socioeconomic group. For women of all ages, the prevalence of all three mental illnesses during and after pregnancy increased with greater socioeconomic deprivation (Tables 2-4). After adjusting for calendar 


\section{Table 4. Absolute risks and adjusted odds ratios for serious mental illness associated with socioeconomic status, stratified by maternal age $\left(N=110285^{a}\right)$}

\begin{tabular}{|c|c|c|c|c|c|c|c|c|c|c|c|c|}
\hline \multirow{3}{*}{$\begin{array}{l}\text { Socioeconomic status } \\
\text { (deprivation quintile) }\end{array}$} & \multicolumn{11}{|c|}{ Maternal age } & \multirow[b]{3}{*}{$\operatorname{AOR}^{d}(95 \% \mathrm{Cl})$} \\
\hline & \multicolumn{3}{|c|}{$15-24$ years } & \multirow[b]{2}{*}{$\operatorname{AOR}^{d}(95 \% \mathrm{Cl})$} & \multicolumn{3}{|c|}{$25-34$ years } & \multicolumn{4}{|c|}{$35-45$ years } & \\
\hline & $N^{p}$ & nf & $\%$ & & $N^{p}$ & $n f$ & $\%$ & $\operatorname{AOR}^{d}(95 \% C l)$ & $N^{p}$ & $n f$ & $\%$ & \\
\hline During pregnancye & 20176 & 13 & 0.06 & & 60722 & 48 & 0.08 & & 29387 & 44 & 0.15 & \\
\hline 1 (least deprivation) ( $N=26$ 984) & 1843 & 1 & 0.05 & 1.00 & 15732 & 7 & 0.04 & 1.00 & 9409 & 6 & 0.06 & 1.00 \\
\hline $2(N=21978)$ & 2479 & 0 & --- & --- & 12655 & 7 & 0.06 & 1.24 (0.44 to 3.54$)$ & 6844 & 5 & 0.07 & 1.14 (0.35 to 3.73$)$ \\
\hline $3(N=23028)$ & 4052 & 3 & 0.07 & $1.37(0.14$ to 13.22$)$ & 13069 & 8 & 0.06 & 1.39 (0.50 to 3.82$)$ & 5907 & 8 & 0.14 & $2.12(0.73$ to 6.11$)$ \\
\hline $4(N=21771)$ & 5838 & 4 & 0.07 & 1.29 (0.14 to 11.53$)$ & 11452 & 14 & 0.12 & 2.84 (1.14 to 7.04 ) & 4481 & 12 & 0.27 & $4.28(1.60$ to 11.41$)$ \\
\hline $\begin{array}{l}5 \text { (most deprivation) ( } N=16524) \\
P \text {-value for trend }\end{array}$ & 5964 & 5 & 0.08 & $\begin{array}{c}1.59(0.19 \text { to } 13.64) \\
0.30^{f}\end{array}$ & 7814 & 12 & 0.15 & $\begin{array}{c}3.70(1.45 \text { to } 9.42) \\
0.001^{\dagger}\end{array}$ & 2746 & 13 & 0.47 & $\begin{array}{c}7.68(2.92 \text { to } 20.24) \\
<0.001^{\dagger}\end{array}$ \\
\hline $\begin{array}{l}\text { During the } 9 \text { months } \\
\text { after pregnancy }\end{array}$ & 20176 & 25 & 0.12 & & 60722 & 81 & 0.13 & & 29387 & 64 & 0.22 & \\
\hline 1 (least deprivation) ( $N=26$ 984) & 1843 & 1 & 0.05 & 1.00 & 15732 & 15 & 0.10 & 1.00 & 9409 & 13 & 0.14 & 1.00 \\
\hline $2(N=21978)$ & 2479 & 1 & 0.04 & 0.75 (0.05 to 11.98$)$ & 12655 & 17 & 0.13 & 1.42 (0.71 to 2.84 ) & 6844 & 9 & 0.13 & 0.95 (0.41 to 2.23) \\
\hline $3(N=23028)$ & 4052 & 3 & 0.07 & $1.38(0.14$ to 13.28$)$ & 13069 & 13 & 0.10 & 1.06 (0.50 to 2.22) & 5907 & 11 & 0.19 & 1.34 (0.60 to 3.00$)$ \\
\hline $4(N=21771)$ & 5838 & 12 & 0.21 & $3.85(0.50$ to 29.66$)$ & 11452 & 25 & 0.22 & 2.35 (1.24 to 4.47$)$ & 4481 & 15 & 0.33 & $2.42(1.15$ to 5.11$)$ \\
\hline $\begin{array}{l}5 \text { (most deprivation) ( } N=16524) \\
P \text {-value for trend }\end{array}$ & 5964 & 8 & 0.13 & $\begin{array}{c}2.52(0.31 \text { to } 20.16) \\
0.13^{f}\end{array}$ & 7814 & 11 & 0.14 & $\begin{array}{c}1.54(0.70 \text { to } 3.36) \\
0.06^{f}\end{array}$ & 2746 & 16 & 0.58 & $\begin{array}{c}4.20(2.01 \text { to } 8.78) \\
<0.001^{\dagger}\end{array}$ \\
\hline
\end{tabular}

Note: Serious mental illness includes bipolar disorder, schizophrenia or other related psychotic disorders. ${ }^{5} .3 \%$ (6172) of the original population (116 457) had no socioeconomic

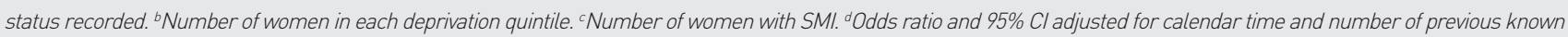
live births. SMI = serious mental illness. ${ }^{e}$ Likelihood ratio test for interaction between deprivation quintile and age group: during pregnancy P =0.79; after pregnancy $\mathrm{P}=0.39$. 'P-value for trend from least to most deprivation excluding women with missing information for socioeconomic status. AOR=adjusted odds ratio.

time and number of previously recorded live births, the odds of perinatal mental illness increased with each deprivation quintile, compared to women in the least socioeconomically-deprived quintile. In the youngest age group, several $95 \%$ confidence intervals (Cls) included unity, however, tests for trend with increasing socioeconomic deprivation were $P<0.001$ for depression (Table 2), $P=0.06$ for anxiety (Table 3), and $P=0.30$ and 0.13 for SMI during and after pregnancy (Table 4), which affected very few women. In older women, the degree of increase in odds of all three clinical mental illnesses with greater socioeconomic deprivation was more marked. For example, women aged $35-45$ years from the most socioeconomically-deprived quintile had 2.6 times the odds of antenatal depression (OR $=2.63,95 \% \mathrm{Cl}=2.22$ to 3.13$), 2.5$ times the odds of anxiety (OR $=2.48,95 \%$ $\mathrm{Cl}=1.98$ to 3.11$)$ and 7.7 times the odds of SMI (OR $=7.68,95 \% \mathrm{Cl}=2.92$ to 20.24$)$ as those from the least socioeconomicallydeprived quintile whereas in women aged 15-24 years, the equivalent ORs were 1.35 $(95 \% \mathrm{Cl}=1.07$ to 1.70$), 1.49(95 \% \mathrm{Cl}=1.06$ to 2.09$)$ and $1.59(95 \% \mathrm{Cl}=0.19$ to 13.64$)$ respectively (Tables $2-4$ ). Similar patterns of risks were found postnatally. The $P$-values from the likelihood ratio tests for interaction between socioeconomic deprivation quintile and maternal age group were $<0.001$ for antenatal depression, postnatal depression and antenatal anxiety, and 0.09 for postnatal anxiety; however there was weak statistical evidence for such interaction in SMI 0.79 antenatal and 0.39 postnatal) with fairly small numbers of women in each age group.

After restricting to women's first clinical recording of mental illness, prevalence estimates of all three mental illnesses presenting initially during or after pregnancy were substantially reduced across all age and socioeconomic group. The impact of socioeconomic deprivation also reduced, yet patterns of increasing ORs with greater deprivation generally persisted. The degree of increase with deprivation quintile was again greatest in women aged $35-45$ years for antenatal depression, antenatal and postnatal anxiety, but not for postnatal depression which was instead greatest in women aged 15-24 years. Since very few women had a first clinical recording of SMI during or after pregnancy, it was not possible to stratify by age. Although adjusted ORs showed an association with deprivation, 95\% Cls were extremely wide (data on first clinical recording are available on request from the authors).

\section{DISCUSSION}

Summary

A substantial burden of depression, anxiety, 
and SMI during the perinatal period presents and is managed in UK general practice among women with pregnancies ending in live births, although there are important socioeconomic inequalities in absolute risk. Higher risks of mental illness in mothers in more socioeconomicallydeprived areas compared with those in less deprived areas persist with increasing maternal age. When women's initial clinical presentation of mental illness was during or after pregnancy, the impact of socioeconomic deprivation remained yet reduced, indicating that this was partially due to a history of mental illness commonly recurring in the perinatal period.

\section{Strengths and limitations}

To the authors' best knowledge, this is the largest study to examine the clinical prevalence and overlap of maternal depression, anxiety and SMI presenting to general practice in and around pregnancy. It is also the first to assess the joint effect of maternal age and socioeconomic status on the clinical burden of maternal perinatal mental illness in the UK. This study's considerable sample size means that these findings are unlikely to be due to chance. Equally as data were obtained from a large general practice database with prospective recording, recall bias of mental illness was excluded.

This study's definition of maternal mental illness relies on women presenting to and being correctly identified by practitioners. Such estimates quantify the primary care burden in pregnancy, thus excluding undiagnosed illness in women not disclosing feelings to their doctor or health visitor. ${ }^{16} \mathrm{~A}$ range of diagnostic tools (for example, the Edinburgh Postnatal Depression Scale) has been used in cohort studies of selected populations, yet there is no universal agreement that these are advantageous in a routine clinical setting (or for screening) and as such there are no widely applied cutoffs used in practice to diagnose mental illness. ${ }^{17,18}$ Case identification was based on diagnostic and prescribing records to reflect routine practice, similar to methods used by the Office for National Statistics and other published studies of mental illness in general practice databases. ${ }^{19-22}$ Since GPs occupy a gate-keeper role to health care, and are normally the first point of contact for non-emergency services, referred via midwives and health visitors, it is thought that these data are an ideal source for estimating the prevalence of mental illness presenting to general practice nationally. The similarity of this study's prevalence estimates to studies restricting to diagnosed postnatal depression using standardised interviewing schedules ${ }^{23,24}$ and anxiety ${ }^{25}$ is reassuring. The decreased prevalence observed during pregnancy may reflect NICE guidelines to reduce psychotropic drug treatment during pregnancy which has been observed elsewhere, ${ }^{26}$ greater midwifery care antepartum, or diagnostic bias if GPs remain more likely to diagnose and treat mental illness postpartum.

\section{Comparison with existing literature}

Although numerous studies have estimated the prevalence of maternal depression, fewer have assessed anxiety and SMI and this study is the first to compare prospectively all clinically-recognised mental illnesses (depression, anxiety and SMI) and their concurrence before, during and after pregnancy in UK general practice. A systematic review of highincome countries found the prevalence of maternal postnatal depression was $13 \%,{ }^{23}$ however individual study estimates varied widely. A systematic review of maternal anxiety concluded that there were too few studies to obtain adequate estimates around pregnancy; in three small studies generalised anxiety disorder ranged from 4.4-8.2\% postpartum. ${ }^{25}$ Most previous studies assessed mental illness by studyspecific screening with self-administered questionnaires, ${ }^{27}$ which means they are not directly comparable with this study.

Previous studies on SMI primarily rely on medical admissions and this study's similar estimates indicate diagnoses are reasonably captured among women registered in general practice. Nager and colleagues $^{12}$ examined Swedish first-time mothers ( $n=502767$ ) and found about $0.07 \%$ had a first hospital admission for psychosis postpartum, very similar to this study's estimate of first recorded SMI. This study's estimates also concur with a 1987 Edinburgh registry study ${ }^{28}$ in which a higher proportion of psychiatric admissions presented after childbirth than during pregnancy. In Denmark, Munk-Olsen and colleagues ${ }^{29}$ examined over 1 million firsttime mothers and found that compared with 6-11 months postpartum, medical contact for any mental disorder was more likely during the first month postpartum (relative risk $=3.49$ ), and less likely during pregnancy (relative risk $=0.72$ ), which is consistent with this study's findings.

Sociodemographic factors have important impacts on maternal mental illness yet the joint effects of maternal age and socioeconomic deprivation this article on the Discussion Forum: http://www.rcgp.org.uk/bjgp-discuss 
among pregnant women and new mothers as predictors of important health burden in the population have not been adequately assessed. A recent US study ${ }^{30}$ of more than 75000 non-pregnant women aged 18-44 years found that the prevalence of major depression was greater in women $>35$ years, unmarried, less educated, unable to work or unemployed or with low income than in women without such risk factors. Previous studies $10,11,23,31$ show that women with greater socioeconomic deprivation are more likely to have perinatal mental illness than those with less socioeconomic deprivation after adjusting for other sociodemographic factors.

Rich-Edwards and colleagues ${ }^{10}$ interviewed 1662 women from Boston in the US and found an increased odds of postnatal depression in those with financial hardship lOR $=3.6,95 \%$ $\mathrm{Cl}=1.9$ to 6.7 after adjusting for maternal age, race/ethnicity, immigration status, parity and income). As in this study's UK population many women had a history of depression, which was by far the strongest risk factor for perinatal depression; however the effect of financial hardship remained when they excluded women with a history of depression.
Women aged $<23$ years had more maternal depression during and after pregnancy than women aged 30-34 years $\mathrm{COR}=2.7,95 \%$ $\mathrm{Cl}=1.4$ to 5.2 mid-pregnancy and $\mathrm{OR}=2.4$, $95 \% \mathrm{Cl}=1.1$ to $5.4,6$ months postpartum after adjusting for race/ethnicity); however effects reduced and were not statistically significant after adjusting for household income, suggesting that effect of maternal age was largely driven by different financial circumstances.

\section{Implications for practice and research}

The considerable primary care burden of maternal perinatal mental illness found in this study highlights that women in more socioeconomically-deprived circumstances are at high risk, which needs greater recognition at policy level. As there is currently not enough evidence that perinatal screening tools are advantageous over clinical assessment in routine practice, 17,18 this should emphasise the need for trials of methods to effectively identify women and interventions to prevent and treat perinatal mental illness among high-risk women in the primary care setting. 


\section{REFERENCES}

1. Oates M. Perinatal psychiatric disorders: a leading cause of maternal morbidity and mortality. Br Med Bull 2003; 67: 219-229.

2. Jablensky AV, Morgan V, Zubrick SR, et al. Pregnancy, delivery, and neonatal complications in a population cohort of women with schizophrenia and major affective disorders. Am J Psychiatry 2005; 162(1): 79-91.

3. Howard LM, Goss C, Leese M, Thornicroft G. Medical outcome of pregnancy in women with psychotic disorders and their infants in the first year after birth. $\mathrm{Br} J$ Psychiatry 2003; 182(1): 63-67.

4. Servili C, Medhin G, Hanlon C, et al. Maternal common mental disorders and infant development in Ethiopia: the P-MaMiE Birth Cohort. BMC Public Health 2010; 10(1): 693

5. Ban L, Gibson J, West J, Tata L. Association between perinatal depression in mothers and the risk of childhood infections in offspring: a population-based cohort study. BMC Public Health 2010; 10(1): 799.

6. National Institute for Health and Clinical Excellence. Antenatal and postnatal mental health. CG 45. 2007. http://guidance.nice.org.uk/CG45 laccessed 30 Aug 2012).

7. Gavin NI, Gaynes BN, Lohr KN, et al. Perinatal depression: a systematic review of prevalence and incidence. Obstet Gynecol 2005; 106(5 Pt 1): 1071-1083.

8. HM Government. No health without mental health: a cross-government mental health outcomes strategy for people of all ages. London: DoH, 2011. http://wnw.dh.gov.uk/en/Publicationsandstatistics/Publications/ PublicationsPolicyAndGuidance/DH_123766 (accessed 30 Aug 2012).

9. Lorant $\mathrm{V}$, Deliège $\mathrm{D}$, Eaton $\mathrm{W}$, et al. Socioeconomic inequalities in depression: a meta-analysis. Am J Epidemiol 2003; 157(2): 98-112.

10. Rich-Edwards JW, Kleinman K, Abrams A, et al. Sociodemographic predictors of antenatal and postpartum depressive symptoms among women in a medical group practice. J Epidemiol Community Health 2006; 60(3): 221-227.

11. Hobfoll SE, Ritter C, Lavin J, et al. Depression prevalence and incidence among inner-city pregnant and postpartum women. J Consult Clin Psychology 1995 63(3): 445-453.

12. Nager A, Johansson L-M, Sundquist K. Are sociodemographic factors and year of delivery associated with hospital admission for postpartum psychosis? A study of 500000 first-time mothers. Acta Psychiat Scand 2005; 112(1): 47-53.

13. Valdimarsdóttir U, Hultman CM, Harlow B, et al. Psychotic illness in first-time mothers with no previous psychiatric hospitalizations: a population-based study. PLoS Med 2009; 6(2): e13

14. Kreitman N, Carstairs V, Duffy J. Association of age and social class with suicide among men in Great Britain. J Epidemiol Community Health 1991; 45(3): 195-202.

15. Lewis JD, Schinnar R, Bilker WB, et al. Validation studies of the health improvement network (THIN) database for pharmacoepidemiology research.
Pharmacoepidemiol Drug Saf2007; 16(4): 393-401

16. Chew-Graham CA, Sharp D, Chamberlain E, et al. Disclosure of symptoms of postnatal depression, the perspectives of health professionals and women: a qualitative study. BMC Fam Pract 2009; 10: 7.

17. Oates M. Postnatal depression and screening: too broad a sweep? Br J Gen Pract 2003; 53(493): 596-597.

18. Leverton TJ, Elliott SA. Is the EPDS a magic wand?: 1. A comparison of the Edinburgh Postnatal Depression Scale and health visitor report as predictors of diagnosis on the Present State Examination. J Reprod Infant Psychol 2000; 18(4): 279-296.

19. Rait $\mathrm{G}$, Walters $\mathrm{K}$, Griffin M, et al. Recent trends in the incidence of recorded depression in primary care. Br J Psychiatry 2009; 195(6): 520-524.

20. Dave S, Petersen I, Sherr L, Nazareth I. Incidence of maternal and paternal depression in primary care: a cohort study using a primary care database. Arch Pediatr Adolesc Med 2010; 164(11): 1038-1044.

21. Martín-Merino E, Ruigómez A, Wallander M-A, et al. Prevalence, incidence, morbidity and treatment patterns in a cohort of patients diagnosed with anxiety in UK primary care. Fam Pract 2010; 27(1): 9-16.

22. Moser K, Majeed A, Office for National Statistics. Prevalence of treated chronic diseases in general practice in England and Wales; trends over time and variations by the ONS area classification. London: Office for National Statistics, 1999

23. O'Hara MW, Swain AM. Rates and risk of postpartum depression-a metaanalysis. Int Rev Psychiatry 1996; 8(1): 37-54.

24. Cox JL, Murray D, Chapman G. A controlled study of the onset, duration and prevalence of postnatal depression. Br J Psychiatry 1993; 163: 27-31.

25. Ross LE, McLean LM. Anxiety disorders during pregnancy and the postpartum period: a systematic review. J Clin Psychiatry 2006; 67(8): 1285-1298.

26. Petersen I, Gilbert RE, Evans SJW, et al. Pregnancy as a major determinant for discontinuation of antidepressants: an analysis of data from The Health Improvement Network. J Clin Psychiatry 2011; 72(7): 979-985.

27. Evans J, Heron J, Francomb H, et al. Cohort study of depressed mood during pregnancy and after childbirth. BMJ 2001; 323(7307): 257-260.

28. Kendell R, Chalmers J, Platz C. Epidemiology of puerperal psychoses. Br J Psychiatry 1987; 150(5): 662-673.

29. Munk-Olsen T, Laursen TM, Pedersen CB, et al. Family and partner psychopathology and the risk of postpartum mental disorders. J Clin Psychiatry 2007; 68(12): 1947-1953.

30. Farr SL, Bitsko RH, Hayes DK, Dietz PM. Mental health and access to services among US women of reproductive age. Am J Obstet Gynecol 2010; 203(6): 542 e1-9

31. Warner R, Appleby L, Whitton A, Faragher B. Demographic and obstetric risk factors for postnatal psychiatric morbidity. Br J Psychiatry 1996; 168(5): 607-611. 